\title{
Transmission Loss allocation with Optimal Power Flow using Gravitational Search Algorithm
}

\author{
N. V. Subba Rao ${ }^{1}$, G. Kesava Rao ${ }^{2}$, S. Sivanagaraju ${ }^{3}$ \\ Associate professor, Department of EEE, LBRCE, Mylavaram, A.P., India ${ }^{1}$ \\ Professor, Department of EEE, KL University, Guntur, A.P., India ${ }^{2}$ \\ Professor, Department of EEE, JNTUK, Kakinada, A.P., India ${ }^{3}$
}

\begin{abstract}
In deregulated power systems, the transmission loss allocation plays a key role in planning and designing of the power system. In practice, these losses should be allocated to both generators and loads depending on the amount of contribution in the total power system losses. In this paper, a new methodology to optimally allocate the transmission losses to either generators or loads based on the power flow tracing methodology is presented. In this methodology, trace usage coefficients are formulated to allocate transmission losses. In real time, system operator tries to minimize the transmission losses to increase the security of the system. In this paper, for the sack of analysis, the formulated OPF problem with transmission losses as objective is solved while satisfying system constraints using gravitational search algorithm. The minimized transmission losses are then allocated to either generators or loads. The proposed methodology is tested on standard IEEE-30 bus and real time Indian-24 bus test systems with supporting numerical results.
\end{abstract}

Keywords: Transmission loss allocation, Power flow tracing, Optimal power flow, Trace usage coefficients

\section{INTRODUCTION}

Now a day, because of the open access environment, each of the loads has an advantage to use the power from the required generator. Due to this, the complexity of power system is increasing and sometimes leads to insecure condition such as system collapse. Similarly, the transmission losses in a system are increased drastically and the cost of this should be allocated to generators or loads based on the contractual agreements. To solve this, it is necessary to trace the power flow in a given system, to allocate the transmission losses to generators or loads based on the amount of generation or amount of the power consumed by the load.

Tracing of active power and reactive power are given. $[1,2]$ as far as reactive flows are concerned, the lines are considered as sources or sinks; this is very different from the behavior of active power flows for which the lines are always simple 'carriers with losses'. In [3], a methodology for active power flow tracing is outlined; the authors say that such methodology is also suitable for reactive power tracing; but the applications only concern active power flow tracing. In the interconnected systems, power flows in the transmission lines in which how the power flow between generator/ loads and flows is given by sensitive analysis $[4,5]$. The tracing of power permits the system operator to incorporate the level of system usage for pricing the transmission services. It also helps to estimate some of the resources required in the form of ancillary services [6-8]. References [9-12] proposed power tracing algorithms.

In [13], a tracing algorithm is proposed which did not describe as to how to extend the same to cases where the reactive power flows from both ends of the line. The most

Copyright to IJIREEICE famous scheme is tracing of electricity which simple and understandable to market participants. In [14], the matrix power series has been used to get inversion of upstream and downstream tracing distribution matrices giving some important inferences. In [15], an attempt was made to get relationship between the generator (or loads) and power flows by means of sensitivity analysis, that is by determining how the flow is influenced a change in a nodal generation/ demand in a particular line [16]. In $[17,18]$, electricity tracing technique is proposed under the assumption that nodal inflows are shared proportionally between the nodal outflows, allowing one to trace the flow of electricity on interconnected network. With which, share of each generator in each line flow and load can be determined. Same concept was proposed in [19].

The loss compensation schemes to balance actual loss and recovered loss is employed by IGO [20]. The transmission loss compensation schemes considered as ancillary services are presented in [21-23]. The major factors in the locational spot pricing is transmission loss allocation amounting 3-5\% of total generation [24]. In [25], an attempt is made that the difference between the sum of theoretically allocated losses and the actual system loss are reduced. In [26-32] the concept of distributed slack bus is introduced. In this method loses allocated to busses are exactly equal to actual loss which is given by ac power flow. Some meta-heuristic methods such as fast evolutionary programming (FEP) [33], particle swarm optimization (PSO) [34], hybrid quantum PSO (HQPSO) [35], and differential evolution (DE) [36], were applied to solve OPF problems with valve-point effects. Artificial bee colony (ABC) [37], artificial immune system (AIS) 
[38] and chaotic particle swarm optimization (CPSO) [39] usage coefficients are formulated. In this paper, were utilized in OPF problems with prohibited operating gravitational search algorithm is used to solve OPF zones. For economic dispatch problems, evolutionary problem with transmission loss as objective while programming (EP) [40], real coded genetic algorithm satisfying system constraints. The minimized transmission (RCGA) [41] and time-varying acceleration coefficients losses are then allocated to generators or loads. The PSO (TVAC-PSO) [42] were used. Differential harmony proposed methodology is tested on standard IEEE-30 bus search (DHS) [43] and adaptive PSO (APSO) [44] were and Indian-24 bus test systems.

proposed to solve OPF problems.

Computational intelligent-based techniques, such as genetic algorithm (GA) [45], improved GA [46], real parameter GA [47], adaptive GA [48], evolutionary programming (EP) [49], particle swarm optimization(PSO) [50], hybrid PSO [51], bacterial foraging optimization(BFO) [52], differential evolution (DE) [53-55], seeker optimization algorithm (SOA) [56], gravitational search algorithm (GSA) [57], etc, have been applied for solving ORPD problem. These techniques have shown effectiveness in overcoming the disadvantages in traditional methods. Mainly, As far as researchers are concerned, PSO and DE are important techniques because they are efficient techniques. Even they are efficient methods; they attract local optima against global optima. Further, their searching performance depends on the appropriate parameter settings [58]. Premature convergence and local stagnation are frequently observed in many applications.

Gravitations search algorithm (GSA) is based on law of gravity and interaction with masses. In GSA, searcher agents are collection of masses and their interactions are based on Newton laws of gravity and motion. In this paper, to further improve the optimization performance of GSA, opposition-based learning is employed in opposition-based gravitational search algorithm (OGSA) for population initialization and also for generation jumping. In the present work, OGSA is applied for the solution of optimal reactive power dispatch (ORPD) of power systems. Traditionally, ORPD is defined as the minimization of active power transmission losses by controlling a number of control variables. ORPD is formulated as a non-linear constrained optimization problem with continuous and discrete variables. In this work OGSA is used to find the settings of control variables such as generator voltages, tap positions of tap changing transformers and amount of reactive power compensation to optimize certain objectives.

In [59], gravitational search has been discussed. Metaphor of gravitational interactions between masses based gravitational search algorithm is discussed. GSA is developed based theory of Newton's laws: every participle in the universe attracts every other particle with a force that is directly proportional to the product of their masses and inversely proportional to the square of the distance between them.

From the careful review of the literature, it is identified that, the transmission losses should be allocated to generators or loads based on the amount of the power generation or power consumption. For this, it is necessary to trace the power flow in a given system. In this paper, a new methodology based on power flow tracing is proposed. The power flow tracing in turn uses the proportional sharing principle. In this methodology, trace Copyright to IJIREEICE

\section{OPF PROBLEM FORMULATION}

In its general form, the OPF problem can be mathematically represented as

Minimize $\quad f(x, u)$

subjected to $g(x, u)=0 ; h_{\min } \leq h(x, u) \leq h_{\max }$

(2)

where

$f(x, u)$ is the objective function

' $x$ ' is the vector of dependent variables

' $u$ ' is the vector of independent or control variables

$\mathrm{g}(\mathrm{x}, \mathrm{u})$ represents equality constraints

$\mathrm{h}(\mathrm{x}, \mathrm{u})$ represents inequality constraints.

The OPF solution determines a set of optimal variables to achieve a certain goal such as minimum generation cost, power loss etc., subjected to all the equality and inequality constraints. The dependent variables are slack bus active power, load bus voltage magnitudes and its angles, generators reactive powers and line flow limits. The independent variables consist of continuous and discrete variables. The continuous variables are active powers of all generators, except slack bus and generator voltages. The discrete variables are tap settings of regulating transformers and reactive power injections.

\section{A. Transmission power loss (TPL)}

The losses are calculated from the load flows. The power flow from ith bus to jth bus is given by Sij. and that for the power flow from jth bus to ith bus is given by $\mathrm{Sji}$.

$$
L_{i j}=S_{i j}+S_{j i} \mathrm{MW}
$$

The total power loss bus system is given by

$$
\text { Ploss }=\sum_{k=1}^{N T L} \operatorname{real}\left(L_{i j}(k)\right) \mathrm{MW}
$$

Where NTL is total number of transmission lines,

\section{B. Equality constraints}

The equality constraints represent the set of nonlinear power flow equations as

$$
\begin{aligned}
& \sum_{i=1}^{N_{G}} P_{G_{i}}-P_{D}-P_{L}=0 \\
& \sum_{i=1}^{N_{G}} Q_{G_{i}}+Q_{s h}-Q_{D}-Q_{L}=0
\end{aligned}
$$

where Pgi and Qgi are the active and reactive power generations of ith unit, Pd and Qd are the active and reactive load demands of the system, Qsh is the reactive power injection of the shunt compensator, PL and QL are the active and reactive power losses of the system.

\section{Inequality constraints}

The following are inequality constraints for OPF problem Generator bus voltage limits: 


$$
V_{G_{i}}^{\min } \leq V_{G_{i}} \leq V_{G_{i}}^{\max } ; \quad \forall i \in N_{G}
$$

Active Power Generation limits:

$$
P_{G_{i}}^{\min } \leq P_{G_{i}} \leq P_{G_{i}}^{\max } ; \quad \forall i \in N_{G}
$$

Transformers tap setting limits:

$$
T_{i}^{\min } \leq T_{i} \leq T_{i}^{\max } ; \quad i=1,2, \ldots, n_{t}
$$

Capacitor reactive power generation limits:

$$
Q_{S h_{i}}^{\min } \leq Q_{S h_{i}} \leq Q_{S h_{i}}^{\max } ; \quad i=1,2, \ldots, n_{C}
$$

Transmission line flow limit:

$$
S_{l_{i}} \leq S_{l_{i}}^{\max } ; \quad i=1,2, \ldots, N_{\text {line }}
$$

Reactive Power Generation limits:

$$
Q_{G_{i}}^{\min } \leq Q_{G_{i}} \leq Q_{G_{i}}^{\max } ; \quad \forall i \in N_{G}
$$

Bus voltage magnitude limits:

$$
V_{i}^{\min } \leq V_{i} \leq V_{i}^{\max } \quad i=1,2, \ldots, N_{\text {load }}
$$

Where, total number of taps, $n_{C}$ total number of $\mathrm{VAr}$ sources, $N_{\text {load }}$ total number of VAr sources.

\section{III.Gravitational Search Algorithm}

In GSA, each mass (agent) has four specifications: position, inertial mass, active gravitational mass, and passive gravitational mass. The position of the mass corresponds to a solution of the problem, and its gravitational and inertial masses are determined using a fitness function [56, 57].In other words, each mass presents a solution, and the algorithm is navigated by properly adjusting the gravitational and inertia masses. By lapse of time, we expect that masses be attracted by the heaviest mass. This mass will present an optimum solution in the search space.The gravitational constant, $G$, is initialized at the beginning and will be reduced with time to control the search accuracy. In other words, $G$ is a function of the initial value $(G 0)$ and time $(t)$ :

$$
G(t)=G_{0} * e^{\left(\frac{-\alpha t_{i}}{T}\right)}
$$

where $\alpha$ is a constant,

$t_{i}$ is the iteration number and

$\mathrm{T}$ is the total number of iterations.

Consider a system of $\mathrm{N}$ agents. The position of ith agent is defined as

$$
X_{i}=\left(x_{i}^{1}, \ldots \ldots, x_{i}^{d}, \ldots ., x_{i}^{n}\right) \quad i=1,2,3 \ldots, N
$$

For each position fitness function is evaluated.

\section{A. Calculation of masses}

Let fiti(t) be the fitness function of ith particle at th iteration.

Now we introduce new variables worst $(\mathrm{t})$ and best $(\mathrm{t})$.

For a minimization problem, worst $(\mathrm{t})$ and best $(\mathrm{t})$ are defined as follows:

$$
\begin{aligned}
& \operatorname{best}(t)=\min _{j=1,2 \ldots \ldots N} f i t_{j}(t), \\
& \operatorname{worst}(t)=\max _{j=1,2 \ldots \ldots N} f i t_{j}(t),
\end{aligned}
$$

For a maximization problem, worst $(\mathrm{t})$ and best $(\mathrm{t})$ are defined as follows:

$$
\begin{aligned}
& \operatorname{best}(t)=\max _{j=1,2 \ldots \ldots N} f i t_{j}(t), \\
& \operatorname{worst}(t)=\min _{j=1,2 \ldots \ldots N} f i t_{j}(t),
\end{aligned}
$$

Gravitational and inertia masses are simply calculated by the fitness evaluation. A heavier mass means a more efficient agent. This means that better agents have higher attractions and walk more slowly. Assuming the equality of the gravitational and inertia mass, the values of masses are calculated using the map of fitness. We update the gravitational and inertial masses by the following equations:

$$
\begin{aligned}
& M_{a i}=M_{p i}=M_{i i}=M_{i} \\
& m_{i}(t)=\frac{\operatorname{fit}_{i}(t)-\operatorname{worst}(t)}{\operatorname{best}(t)-\operatorname{worst}(t)} \\
& M_{i}(t)=\frac{m_{i}(t)}{\sum_{j=1}^{N} m_{i}(t)}
\end{aligned}
$$

\section{B. Calculation of Force}

For iteration $t$, we define the force acting on mass i from mass $\mathrm{j}$ as following

$$
F_{i j}^{d}(t)=G(t) \frac{M_{p i}(t) M_{a j}(t)}{R_{i j}+\varepsilon}\left(x_{j}^{d}-x_{i}^{d}\right)
$$

where $M a j$ is the active gravitational mass related to agent $j$,

$M p i$ is the passive gravitational mass related to agent $i$,

$G(t)$ is gravitational constant at iteration $t$,

$\varepsilon$ is a small constant and

Rijis the Euclidian distance between two agents $i$ and $j$ given by

$$
R_{i j}(t)=\left\|X_{i}(t), X_{i}(t)\right\|_{2}
$$

To give a stochastic characteristic to our algorithm, we suppose that the total force that acts on agent $i$ in a dimension $d$ be a randomly weighted sum of $d$ th components of the forces exerted from other agents:

$F_{i}^{d}(t)=\sum_{j=1, j \neq i}^{N} \operatorname{rand}_{i} F_{i j}^{d}(t)$

\section{Calculation of Acceleration}

Hence, by the law of motion, the acceleration of the agent at iteration $\mathrm{t}$, and in direction $\mathrm{d}$, is given as:

$a_{i}^{d}=E_{i}^{d}(t) \times G(t)$

Furthermore, the next velocity of an agent is considered as a fraction of its current velocity added to its acceleration. Therefore, its position and its velocity could be calculated as follows:

$$
v_{i}^{d}(t+1)=\operatorname{rand}_{i} \times v_{i}^{d}(t)+a_{i}^{d}(t)
$$$$
x_{i}^{d}(t+1)=x_{i}^{d}(t)+v_{i}^{d}(t+1)
$$ 
IV.Proposed Trace USAGE baSED loss allocation A power flow procedure is used to calculate power loss in the system. It is desirable to take network loss effect of injection power at each node for calculating contribution of transmission loss by each generator and loss allocated to loads and loss allocations to both generators and loads. In this thesis, a tracing based usage coefficients are formulated to implement the loss allocation procedure to generators, loads and both. This methodology starts from a converged load flow solution. Result obtained from the load flow is utilized to further process in this existing methodology to allocate transmission losses to individual generators and individual loads.

\section{A. Power flow tracing mechanism}

Power flow tracing methodology [60] is normally used for calculating generator's share in line flows and loads. After finding generator's share in loads, traced-usage coefficients can be framed for the traced-usage methodology. In this section, procedure of power flow tracing and procedure to formation of traced-usage coefficients can be illustrated.

\section{B. Mathematical modelling of proportional sharing principal}

Consider a bus having two inflows and two outflows as it is convenient to analyze and shown in Fig.1.

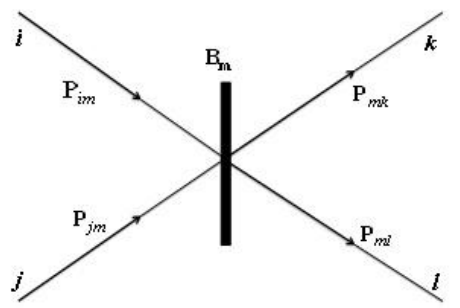

Fig.1. Proportional sharing principal at bus Bm

In Fig.1, Bm is the bus at which power flow tracing explanation is evaluated. $\mathrm{i}, \mathrm{j}, \mathrm{k}$ and $\mathrm{l}$ represents the buses which are connected to Bm through power lines. Pim and Pjm are power inflows to bus Bm. Pmk and Pml are power outflows from bus Bm.

The equations for outflows in terms of inflows can be expressed as

$$
\begin{aligned}
P_{m k} & =\left(\frac{P_{i m}}{P_{i m}+P j m}+\frac{P_{j m}}{P_{i m}+P j m}\right) P_{m k} \\
P_{m l} & =\left(\frac{P_{i m}}{P_{i m}+P j m}+\frac{P_{j m}}{P_{i m}+P j m}\right) P_{m l} \\
Q_{m k} & =\left(\frac{Q_{i m}}{Q_{i m}+Q j m}+\frac{Q_{j m}}{Q_{i m}+Q j m}\right) Q_{m k} \\
Q_{m l} & =\left(\frac{Q_{i m}}{Q_{i m}+Q j m}+\frac{Q_{j m}}{Q_{i m}+Q j m}\right) Q_{m l}
\end{aligned}
$$

From these above four equations we can use only Eqn's (16) and (17), which are real or active power values. This paper deals with active power loss allocation only so that in this concept, the active power will be traced. Reactive power tracing and reactive power loss allocation is under future work.

\section{Trace-Usage Coefficients}

$>\quad T_{i j}^{\alpha}$ is defined as the fraction of power received by the load at $\mathrm{i}^{\text {th }}$ bus to the power generated at $\mathrm{j}^{\text {th }}$ bus.
$T_{i j}^{\beta}$ is defined as the fraction of load power at $\mathrm{j}^{\text {th }}$ bus supplied by the generation at the $\mathrm{i}^{\text {th }}$ bus.

$T_{i j}^{\alpha}=\frac{\text { Active power sharing of } i^{t h} \text { generator in } j^{t h} \text { Load }}{\text { Total }}$

$T_{i j}^{\beta}=\frac{\text { Active power sharing of } i^{t h} \text { generator in } j^{t h} \text { Load }}{\text { Total active power at } j^{t h} \text { load }}$

These $T_{i j}^{\alpha}$ trace-usage coefficients are related to generators, rows indicates generators and columns indicates loads. It gives the details of how much of its generation transfers to loads.

These $T_{i j}^{\beta}$ trace-usage coefficients are related to loads, rows indicates loads and columns indicates generators. It gives the details of how much of its load met by the generators.

\section{Loss Allocation Procedure to Generators}

Consider a power system network with NG generators and NB load (no of buses) connected through a transmission lines. This method separated the non-linear system loss into the sum of NB terms and similarly the sum of NG terms. The main difficulty arises in allocation of loss component to generators and loads because of non linear nature of the loss equation in which the combined set of all traced-usage coefficients interact through the load flow terms. Thus, the loss allocation depends on path and the traced-usage coefficients of generators and loads.

Consider the Generators set $\mathrm{G}=\mathrm{G}_{1}, \mathrm{G}_{2}, \mathrm{G}_{3}, \ldots . . \mathrm{G}_{\mathrm{NG}}$ and the load set $\mathrm{L}=\mathrm{L}_{1}, \mathrm{~L}_{2}, \mathrm{~L}_{3}, \ldots . . \mathrm{L}_{\mathrm{NB}}$.

An exact transmission loss formula using system parameters and bus injected powers is given [40] as follows

$P_{L}=\sum_{i=1}^{N B} \sum_{j=1}^{N B}\left[A_{i j}\left(P_{i} P_{j}+Q_{i} Q_{j}\right)+B_{i j}\left(Q_{i} P_{j}-P_{i} Q_{j}\right)\right]$

Where,

$A_{i j}=\frac{R_{i j}}{\left|V_{i}\right|\left|V_{j}\right|} \cos \left(\delta_{i}-\delta_{j}\right) ; B_{i j}=\frac{R_{i j}}{\left|V_{i}\right|\left|V_{j}\right|} \sin \left(\delta_{i}-\delta_{j}\right)(23)$ $\mathrm{P}_{\mathrm{L}}$ is the real power loss of the power system, $\mathrm{S}_{\mathrm{i}}$ is the injected power at bus $S_{i}=P_{i}+j Q_{i}, Z_{i j}=R_{i j}+j X_{i j}$ and $Z_{i j}$ is the $i-j{ }^{\text {th }}$ element of $Z_{b u s}, V_{i}$ is the voltage magnitude of bus-i and $\delta_{\mathrm{i}}$ is voltage phase angle of bus-i,

E. Loss allocation to generators

The injected real power at bus-i is given as

$$
P_{i}=P_{G i}-P_{\text {Loadi }}
$$

Let $T_{i j}^{\alpha}$ be the traced-usage coefficient that is fraction of power generated at $\mathrm{j}^{\text {th }}$ bus received by the load at $\mathrm{i}^{\text {th }}$ bus.

The load at $i^{\text {th }}$ bus can be expressed as the sum of usage amounts from different generators that is

$$
P_{\text {Loadi }}=\sum_{j=1}^{N G} T_{i j}^{\alpha} P_{G j} \quad \text { where } i=1,2, \ldots, N B
$$

The injected real power can be modified by using above equation as follows

$$
P_{i}=P_{G i}-\sum_{j=1}^{N G} T_{i j}^{\alpha} P_{G j} \quad \text { where } i=1,2, \ldots, N B
$$

The above equation can be rewritten as

$$
P_{i}=\sum_{j=1}^{N G} T_{i j}^{\chi} P_{G j} \quad \text { where } i=1,2, \ldots, N B
$$

where $T_{i j}^{\chi}=-T_{i j}^{\alpha}$ for $i \neq j$ (non-generation buses); $T_{i j}^{\chi}=1-T_{i j}^{\alpha}$ for $i=j$ (generation buses). 
The injected powers at $\mathrm{i}^{\text {th }}$ and $\mathrm{j}^{\text {th }}$ bus can be given as

$P_{i}=\sum_{p=1}^{N G} T_{i p}^{\chi} P_{G p} \quad$ where $i=1,2, \ldots, N B$

$P_{j}=\sum_{q=1}^{N G} T_{i q}^{\chi} P_{G q} \quad$ where $i=1,2, \ldots, N B$

Rearrange the Eqn (22) as components of self power (active or reactive) and mutual-power components

$P_{L}=\sum_{i=1}^{N B} \sum_{j=1}^{N B}\left[A_{i j}\left(P_{i} P_{j}\right)+B_{i j}\left(Q_{i} P_{j}-P_{i} Q_{j}\right)\right]+\left[A_{i j} Q_{i} Q_{j}\right]$

(26)

The above Transmission loss Eqn (26) can be modified by using Eqn's (24) and (25) as follows as

$$
\begin{aligned}
P_{L}= & \sum_{p=1}^{N G}\left\{\left[\sum_{q=1}^{N G}\left(\sum_{i=1}^{N B} \sum_{j=1}^{N B} A_{i j} T_{p i}^{\chi} T_{q i}^{\chi} P_{G p} P_{G q}\right)\right]\right. \\
& \left.+\left[\sum_{i=1}^{N B} \sum_{j=1}^{N B} B_{i j}\left(T_{p j}^{\chi} Q_{i}-T_{p i}^{\chi} Q_{j}\right) P_{G p}\right]+\left[\frac{P_{G p}}{\sum_{p=1}^{N G} P_{G p}} \sum_{i=1}^{N B} \sum_{j=1}^{N B}\left(A_{i j} Q_{i} Q_{j}\right)\right]\right\}
\end{aligned}
$$

(27)

In the above equation the last term is observed that the active power loss caused because of interaction of reactive power injections and it is very small compared to total active power loss. Hence it is assumed that the loss contribution because of interaction of reactive power can be shared to the generators according to its generation.

The loss contribution component (Self Component) because of individual $\mathrm{p}^{\text {th }}$ generator alone is expressed as

$$
\begin{aligned}
& P_{L}^{(p, p)}=\sum_{i=1}^{N B} \sum_{j=1}^{N B} A_{i j} T_{p i}^{\chi} T_{q i}^{\chi} P_{G p}^{2}+\sum_{i=1}^{N B} \sum_{j=1}^{N B} B_{i j}\left(T_{p j}^{\chi} Q_{i}-T_{p i}^{\chi} Q_{j}\right) P_{G p}+ \\
& \frac{P_{G p}}{\sum_{p=1}^{N B} P_{G p}} \sum_{i=1}^{N B} \sum_{j=1}^{N B} A_{i j} Q_{i} Q_{j}
\end{aligned}
$$

$P_{L}^{(p, p)}$ is part of total loss caused by $\mathrm{p}^{\text {th }}$ generator that depends only on its generation.

The loss contribution component (Mutual Component) because of interaction of $\mathrm{p}^{\text {th }}$ generator and $\mathrm{q}^{\text {th }}$ generator is expressed as

$$
P_{L}^{(p, q)}=\sum_{i=1}^{N B} \sum_{j=1}^{N B} A_{i j}\left(T_{p i}^{\chi} T_{q j}^{\chi}+T_{q i}^{\chi} T_{p j}^{\chi}\right) P_{G p} P_{G q}, \quad p \neq q
$$

$P_{L}^{(p, q)}$ is part of total loss caused by interaction of $\mathrm{p}^{\text {th }}$ generator and $\mathrm{q}^{\text {th }}$ generator.

It is common practice that the above term can be allocated to each generator of pair $(p, q)$ as half of the absolute value of $P_{L}^{(p, q)}$ rather than the total amount to individual generators.

$$
P_{L}^{p}=P_{L}^{(p, p)}+\frac{1}{2} \sum_{q=1, q \neq p}^{N G} P_{L}^{(p, q)}
$$

The above procedure can be used for other generators to compute its loss contribution.

The total active power loss is

$$
P_{\text {Tloss }}=\sum_{p=1}^{N G} P_{L}^{p}
$$

\section{F. Loss allocation to loads}

The injected real power at bus-i is given as

$$
P_{i}=P_{G i}-P_{\text {Loadi }}
$$

Let $T_{i j}^{\beta}$ be the traced-usage coefficient that is fraction of power supplied by the generation at ith bus to the load power at jth bus.
The generation at ith bus can be expressed as the sum of usage amounts from different loads that is

$P_{G i}=\sum_{j=1}^{N B} T_{i j}^{\beta} P_{\text {Load } 0 j} \quad$ where $i=1,2, \ldots, N G$

(33)

The injected powers at every bus can be rewritten as below by employ above Eqn's (32) and (33)

$$
P_{i}=\sum_{j=1}^{N B} T_{i j}^{\beta} P_{\text {Loadj }}-P_{\text {Loadi }} \quad \text { where } i=1,2, \ldots, N B
$$

The above equation can be rewritten as

$P_{i}=\sum_{j=1}^{N G} T_{i j}^{\eta} P_{\text {Loadj }} \quad$ where $i=1,2, \ldots, N B$

where $T_{i j}^{\eta}=T_{i j}^{\beta}$ for $i \neq j ; T_{i j}^{\eta}=T_{i j}^{\beta}-1$ for $\mathrm{i}=\mathrm{j}$.

The injected powers at ith and jth bus can be given as $P_{i}=\sum_{p=1}^{N B} T_{i p}^{\eta} P_{\text {Loadp }} \quad$ where $i=1,2, \ldots, N B$

$P_{j}=\sum_{q=1}^{N B} T_{j q}^{\eta} P_{\text {Load } q} \quad$ where $i=1,2, \ldots, N B$

(36)

The above Transmission loss equation Eqn (22) can be modified by using equations Eq's (35) and (36) is follows as

$$
\begin{aligned}
& P_{L}^{\prime}=\sum_{p=1}^{N B}\left\{\left[\sum_{q=1}^{N B}\left(\sum_{i=1}^{N B} \sum_{j=1}^{N B} A_{i j} T_{p i}^{\eta} T_{q i}^{\eta} P_{\text {Loadp }} P_{\text {Loadq }}\right)\right]\right. \\
& \left.+\left[\sum_{i=1}^{N B} \sum_{j=1}^{N B} B_{i j}\left(T_{p j}^{\eta} Q_{i}-T_{p i}^{\eta} Q_{j}\right) P_{\text {Loodp }}\right]+\left[\frac{P_{\text {Loodp }}}{\sum_{p=1}^{N B} P_{\text {Loadp }}} \sum_{i=1}^{N B} \sum_{j=1}^{N B}\left(A_{i j} Q_{i} Q_{j}\right)\right]\right\}
\end{aligned}
$$

In the above equation the last term is observed that the active power loss caused because of interaction of reactive power injections and it is very small compared to total active power loss. Hence it is assumed that the loss contribution because of interaction of reactive power can be shared to the Loads according to its Load capacity.

The loss contribution component (Self Component) because of individual pth load alone is expressed as $P_{L}^{\prime(p, p)}=\sum_{i=1}^{N B} \sum_{j=1}^{N B} A_{i j} T_{p i}^{\eta} T_{p j}^{\eta} P_{\text {Loadp }}^{2}+\sum_{i=1}^{N B} \sum_{j=1}^{N B} B_{i j}\left(T_{p j}^{\eta} Q_{i}-T_{p i}^{\eta} Q_{j}\right) P_{\text {Loadp }}$ $+\frac{P_{\text {loadp }}}{\sum_{p=1}^{N B} P_{\text {Loadp }}} \sum_{i=1}^{N B} \sum_{j=1}^{N B} A_{i j} Q_{i} Q_{j}$

(38)

$P_{L}^{\prime(p, p)}$ is part of total loss caused by pth load that depends only on its load power value.

The loss contribution component (Mutual Component) because of interaction of pth load and qth load is expressed as

$P_{L}^{\prime(p, q)}=\sum_{i=1}^{N B} \sum_{j=1}^{N B} A_{i j}\left(T_{p i}^{\eta} T_{q j}^{\eta}+T_{q i}^{\eta} T_{p j}^{\eta}\right) P_{\text {Loadp }} P_{\text {Loadq }}, \quad p \neq q$

(39)

$P_{L}^{\prime(p, q)}$ is part of total loss caused by interaction of pth load and qth load.

The loss contribution of load at pth bus is given by adding the half of the amount of mutual loss component because of interaction of load-p and load-q to the self component.

$$
P_{L}^{\prime p}=P_{L}^{\prime(p, p)}+\frac{1}{2} \sum_{q=1, q \neq p}^{N B} P_{L}^{\prime(p, q)}
$$

The above procedure can be used for other generators to compute its loss contribution.

www.ijireeice.com 
The total active power loss is

$$
P_{\text {Tloss }}^{\prime}=\sum_{p=1}^{N B} P_{L}^{\prime p}
$$

\section{RESUlts AND ANALYSIS}

In this section, the analysis is performed on standard test systems such as IEEE-30 bus and Indian-24 bus systems.

\section{A. Example-1}

An IEEE-30 bus system with forty one transmission lines, four tap changing transformers and two shunt compensating devices is considered. For this system, there are eighteen control variables, which include active power generation and voltage magnitudes at six generating buses, tap settings of four tap changing transformers, reactive power compensated by two shunt compensators.

Initially, the transmission loss minimization problem formulated in section 2 is solved using the proposed GSA methodology and the corresponding optimal settings of the control variables are tabulated in Table.1. From this table, it is identified that, the total active power generation and consequently the total active power losses are decreased with GSA. In this case, all generators except slack generator are operating at its maximum limits due to which the total transmission losses are minimized is also observed. In the same way, the time taken for the execution is $30.9481 \mathrm{sec}$ with GSA.

The convergence characteristics for the proposed method is shown in Fig.2. From this figure, it is observed that, the proposed method starts the iterative process with good initial value and reaches best final value in less number of iterations.

\begin{tabular}{|c|c|c|c|}
\hline S. No & \multicolumn{2}{|c|}{ Control parameters } & With GSA \\
\hline \multirow{6}{*}{1} & \multirow{6}{*}{ 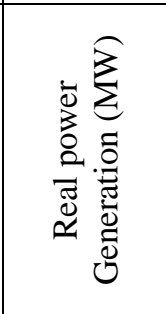 } & $P_{G 1}$ & 51.9567 \\
\hline & & $P_{G 2}$ & 80 \\
\hline & & $P_{G 5}$ & 50 \\
\hline & & $P_{G 8}$ & 35 \\
\hline & & $P_{G 11}$ & 29.7534 \\
\hline & & $P_{G 13}$ & 40 \\
\hline \multirow{6}{*}{2} & \multirow{6}{*}{ 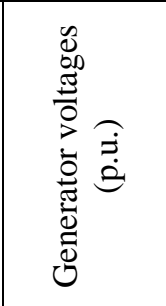 } & $V_{G 1}$ & 1.05 \\
\hline & & $V_{G 2}$ & 1.0459 \\
\hline & & $V_{G 5}$ & 1.0298 \\
\hline & & $V_{G 8}$ & 1.0331 \\
\hline & & $V_{G 11}$ & 1.05 \\
\hline & & $V_{G 13}$ & 1.0494 \\
\hline \multirow{4}{*}{3} & \multirow{4}{*}{ 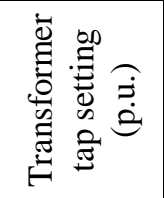 } & $T_{6-9}$ & 1.1 \\
\hline & & $T_{6-10}$ & 0.9 \\
\hline & & $T_{4-12}$ & 1.0167 \\
\hline & & $T_{28-27}$ & 0.9711 \\
\hline \multirow[b]{2}{*}{4} & \multirow{2}{*}{ 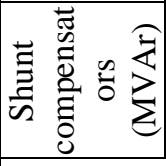 } & $Q_{C, 10}$ & 5 \\
\hline & & $Q_{C, 24}$ & 16.424 \\
\hline 5 & \multicolumn{2}{|c|}{ Total generation (MW) } & 286.71 \\
\hline 6 & \multicolumn{2}{|c|}{ Total power loss (MW) } & 3.31 \\
\hline 7 & \multicolumn{2}{|c|}{ Time $(\mathrm{sec})$} & 30.9481 \\
\hline
\end{tabular}

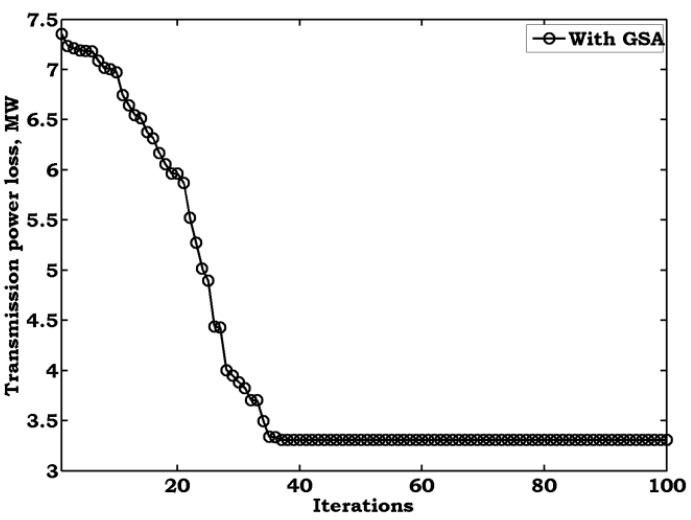

Fig.2. Convergence characteristics with GSA for IEEE-30 bus system

Further, the proposed method is validated with the existing methods and the corresponding information is given in Table.2. From this table, it is confirmed that, the proposed method gives better result when compared to existing methods.

TABLE. 2. COMPARISON OF VARIOUS METHODS OF TRANSMISSION LOSS MINIMIZATION FOR IEEE-30 BUS SYSTEM

\begin{tabular}{|c|c|c|c|}
\hline S. No & Method & $\begin{array}{c}\text { Transmission } \\
\text { losses }(\mathrm{MW})\end{array}$ & $\begin{array}{c}\text { Time } \\
(\mathrm{Sec})\end{array}$ \\
\hline 1 & CPSO [49] & 4.5615 & 138 \\
\hline 2 & DE [53] & 4.555 & NA \\
\hline 3 & Proposed GSA & 3.31 & 30.9481 \\
\hline
\end{tabular}

After minimizing the transmission power losses in a given system using OPF, these losses should be allocated to either generators or loads. To perform this, procedure described in section 4 is used.

\section{Loss allocation to generators:}

Initially using the procedure given in section $4(\mathrm{E})$, the total losses obtained using GSA are allocated to generators alone. Here, from Table.1, the total losses are 3.31 MW with GSA are allocated to six generators which are connected at buses $1,2,5,8,11$ and 13. The corresponding loss allocations are tabulated in Table.3. From this table, it is observed that, maximum losses are allocated to generator placed at bus- 2 in both methods. This is because of the amount of generation is highest when compared to other generators. The graphical representation of loss allocations to all generators is shown in Fig.3.

TABLE.3. LOSS ALLOCATION WITH GSA TO GENERATORS FOR IEEE-30 BUS SYSTEM

\begin{tabular}{|c|c|c|}
\hline S. No & Bus No & $\begin{array}{c}\text { Loss allocation with } \\
\text { GSA (MW) }\end{array}$ \\
\hline 1 & 1 & 1.1723 \\
\hline 2 & 2 & 1.402 \\
\hline 3 & 5 & 0.027 \\
\hline 4 & 8 & 0.1501 \\
\hline 5 & 11 & 0.2131 \\
\hline 6 & 13 & 0.3455 \\
\hline \multicolumn{2}{|r|}{ Total power loss (MW) } & 3.31 \\
\hline
\end{tabular}




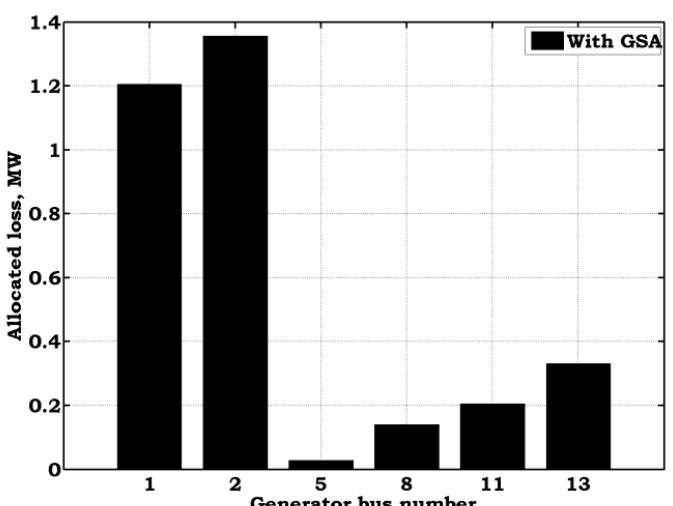

Fig.3. Variation of loss allocation with GSA to generators for IEEE-30 bus system

Loss allocation to loads:

The procedure described in section $4(F)$ is used to allocate losses among the loads. For this system, there are twenty one loads and respective loss allocations using existing and proposed methods are tabulated in Table.4. From this table, it is identified that, maximum losses are allocated to load at bus- 5 as the amount of load at this bus is high i.e. 94.2 MW when compared to other buses. The minimum losses are allocated to load at bus- 8 i.e. $30 \mathrm{MW}$, this is because of the availability of local generation. Hence, it very clear that, maximum amount of load at bus- 8 is supplied from the generator at the same bus. The graphical representation of loss allocations to all loads is shown in Fig.4.

TABLE.4. LOSS ALLOCATION WITH GSA TO LOADS FOR IEEE-30 BUS SYSTEM

\begin{tabular}{|c|c|c|}
\hline S. No & Bus No & $\begin{array}{l}\text { Loss allocations } \\
\text { with GSA (MW) }\end{array}$ \\
\hline 1 & 2 & 0.0381 \\
\hline 2 & 3 & 0.0274 \\
\hline 3 & 4 & 0.0951 \\
\hline 4 & 5 & 0.9805 \\
\hline 5 & 7 & 0.4796 \\
\hline 6 & 8 & 0.0163 \\
\hline 7 & 10 & 0.0307 \\
\hline 8 & 12 & 0.0213 \\
\hline 9 & 14 & 0.0656 \\
\hline 10 & 15 & 0.1153 \\
\hline 11 & 16 & 0.0321 \\
\hline 12 & 17 & 0.0954 \\
\hline 13 & 18 & 0.0655 \\
\hline 14 & 19 & 0.1784 \\
\hline 15 & 20 & 0.0309 \\
\hline 16 & 21 & 0.1884 \\
\hline 17 & 23 & 0.063 \\
\hline 18 & 24 & 0.1654 \\
\hline 19 & 26 & 0.1102 \\
\hline 20 & 29 & 0.0706 \\
\hline 21 & 30 & 0.4402 \\
\hline \multicolumn{2}{|c|}{ Total power loss (MW) } & 3.31 \\
\hline
\end{tabular}

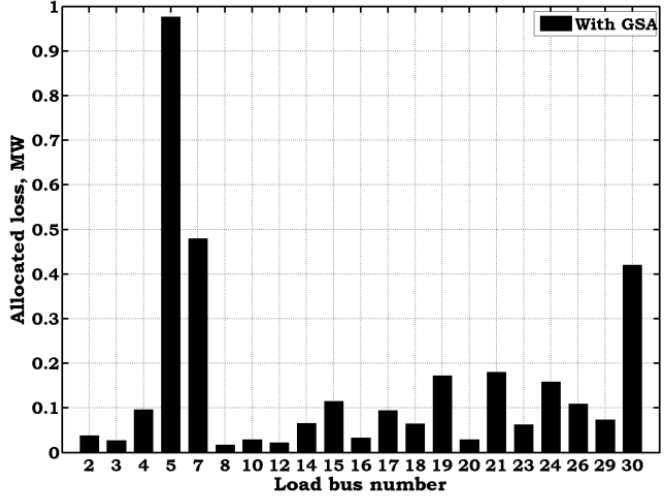

Fig..4. Variation of loss allocation with GSA to loads for IEEE-30 bus system

\section{B. Example-2}

A real time Indian-24 bus system with twenty seven transmission lines, four generating units is considered. For this system, there are eight control variables, which include active power generation and voltage magnitudes of four generating units.

Initially, the transmission loss minimization problem formulated in section 2 is solved using the proposed GSA methodology and the corresponding optimal settings of the control variables are tabulated in Table.5. It is also observed that, the total active power generation and consequently the total active power losses are decreased slightly with GSA. In the same way, the time taken for the execution is $27.9281 \mathrm{sec}$ with GSA.

The convergence characteristics for the proposed and existing methods are shown in Fig.5. From this figure, it is observed that, the proposed method starts the iterative process with good initial value and reaches best final value in less number of iterations.

TABLE.5. OPF RESULTS WITH GSA FOR INDIAN-24 BUS SYSTEM

\begin{tabular}{|c|c|c|c|}
\hline S. No & \multicolumn{2}{|c|}{ Parameter } & With GSA \\
\hline \multirow{4}{*}{1} & \multirow{4}{*}{ 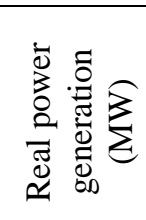 } & $P_{G 1}$ & 524.4233 \\
\hline & & $P_{G_{2}}$ & 117.847 \\
\hline & & $P_{G 3}$ & 205.4282 \\
\hline & & $P_{G 4}$ & 431.1974 \\
\hline \multirow{4}{*}{2} & \multirow{4}{*}{ 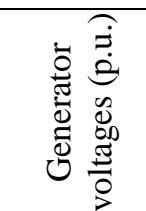 } & $V_{G 1}$ & 1.1 \\
\hline & & $V_{G 2}$ & 0.9952 \\
\hline & & $V_{G 3}$ & 1.0551 \\
\hline & & $V_{G 4}$ & 1.1 \\
\hline 3 & \multicolumn{2}{|c|}{ Total generation (MW) } & 1278.896 \\
\hline 4 & \multicolumn{2}{|c|}{ Total power loss (MW) } & 35.896 \\
\hline 5 & \multicolumn{2}{|c|}{ Time (sec) } & 27.9281 \\
\hline
\end{tabular}




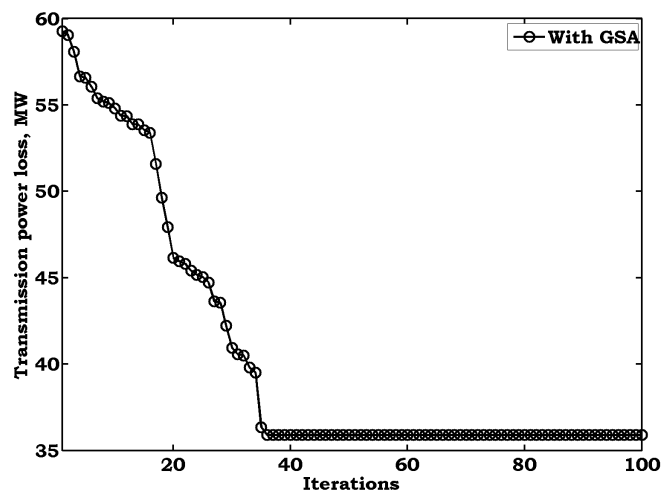

Fig.5 Convergence characteristics with GSA for Indian-24 bus system After minimizing the transmission power losses in a given system using OPF, these losses should be allocated to either generators or loads. To perform this, procedure described in section 4 is used.

\section{Loss allocation to generators:}

Initially using the procedure given in section $4(\mathrm{E})$, the total losses obtained using GSA are allocated to generators alone. Here, from Table.5, the total losses are 35.896 MW with GSA are allocated to four generators which are connected at buses 1, 2, 3 and 4. The corresponding loss allocations are tabulated in Table.6. From this table, it is observed that, maximum losses are allocated to generator placed at bus-1. This is because of the amount of generation is highest when compared to other generators. The graphical representation of loss allocations to all generators is shown in Fig.6.

TABLE.6. LOSS ALLOCATION WITH GSA TO GENERATORS FOR INDIAN-24

\begin{tabular}{|c|c|c|}
\hline \multicolumn{3}{|c|}{ BUS SYSTEM } \\
So & Bus No & $\begin{array}{c}\text { Loss allocations } \\
\text { with GSA (MW) }\end{array}$ \\
\hline 1 & 1 & 17.9211 \\
\hline 2 & 2 & 2.8372 \\
\hline 3 & 3 & 4.2847 \\
\hline 4 & 4 & 10.853 \\
\hline \multicolumn{2}{|c|}{ Total power loss (MW) } & 35.896 \\
\hline
\end{tabular}

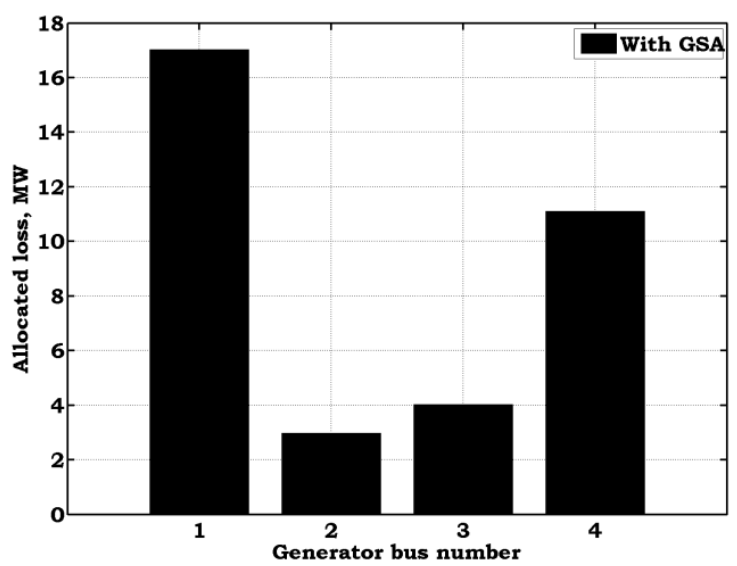

Fig.6 Variation of loss allocation with GSA to generators for Indian-24 bus system

Loss allocation to loads:

The procedure described in section $4(\mathrm{~F})$ is used to allocate losses among the loads. For this system, there are fourteen loads and respective loss allocations using proposed method is tabulated in Table.7. From this table, it is identified that, maximum losses are allocated to load at bus-16 as the amount of load at this bus is high i.e. 230 MW when compared to other buses. The minimum losses are allocated to load at bus-11 i.e. $35 \mathrm{MW}$, this is because of the availability of local generation. Hence, it very clear that, maximum amount of load at bus-11 is supplied from the generator at the same bus. The graphical representation of loss allocations to all loads is shown in Fig.7.

TABLE.7. LOSS ALLOCATION WITH GSA TO LOADS FOR INDIAN-24 BUS SYSTEM

\begin{tabular}{|c|c|c|}
\hline S. No & Bus No & $\begin{array}{c}\text { Loss allocations } \\
\text { with GSA (MW) }\end{array}$ \\
\hline 1 & 6 & 1.5336 \\
\hline 2 & 7 & 6.3918 \\
\hline 3 & 9 & 1.0702 \\
\hline 4 & 10 & 3.3726 \\
\hline 5 & 11 & 0.7265 \\
\hline 6 & 12 & 0.926 \\
\hline 7 & 13 & 4.0988 \\
\hline 8 & 16 & 7.3069 \\
\hline 9 & 17 & 1.9878 \\
\hline 10 & 19 & 2.4692 \\
\hline 11 & 20 & 1.2161 \\
\hline 12 & 21 & 0.9486 \\
\hline 13 & 23 & 1.5426 \\
\hline 14 & 24 & 2.3053 \\
\hline Total power loss (MW) & 35.896 \\
\hline
\end{tabular}

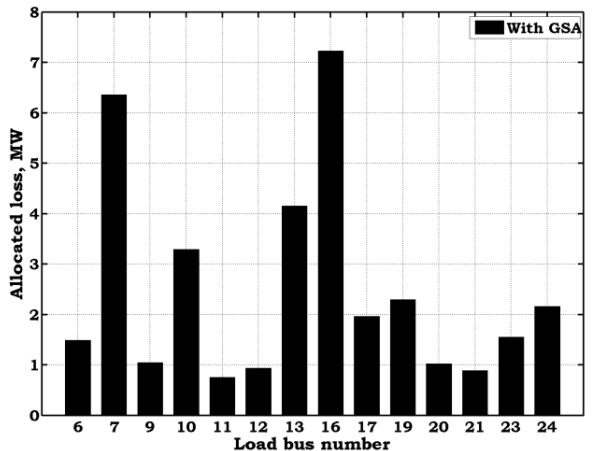

Fig.7. Variation of loss allocation with GSA to loads for Indian-24 bus system

\section{CONCLUSION}

In this paper, gravitational search algorithm has been proposed to enhance the optimization technique performance in terms of convergence characteristics and computational time. Proposed OPF problem with transmission losses as an objective and is solved while satisfying equality and in-equality constraints. Finally the minimized power losses are allocated to generators or/and loads. It is finally observed that, with the proposed tracing based loss allocation mechanism, losses are allocated to generators or loads based on the amount of the generation and the amount of consumption. This is validated with proper explanations. The proposed GSA method is validated with some of the existing methods. Finally, it is summarized that, the proposed loss allocation methodology with the proposed GSA method yields good results on standard systems. 


\section{REFERENCES}

[1] J. Bialek, "Tracing the flow of electricity", IEE Proc. Gen. Transm. Distrib. 143 (1996) 313-320.

[2] J. Bialek, "Allocation of transmission supplementary charge to real and reactive loads", IEEE Trans. Power Syst. 13 (1998) 749-754.

[3] Kirschen, R. Allan, G. Strbac, Contributions of individual generators to loads and flows, IEEE Trans. Power Syst. 12 (1997) 52-60

[4] Rudnick. H., Palma. R., and Fernandez. J. E., "Marginal pricing and supplement cost allocation in transmission open access', IEEE Trans., 1995, PWRS-10, (2), pp. 1125-1142.

[5] NG. W.Y., "Generalized generation distribution factors for power the load from a particular transmission line is given system security evaluations", IEEE Trans., 1981, PAS-100, (3), pp.1001-1005.

[6] Merrill, H.M., and Erickson, B.W.: "Wheeling rates based on marginal-cost theory", IEEE Trans., 1989, PWRS-4, (4), pp. 144514512 Happ, H.H.: 'Cost of wheeling methodologies', IEEE Trans., 1994, PWRS-9, (1), pp. 147-156

[7] Happ, H.H.: "Cost of wheeling methodologies", IEEE Trans., 1994, PWRS-9, (1), pp. 147-156

[8] Shirmohammadi, D., Gribik, P.R., Law, E.T.K., Malinowski, J.H., and O'Donnel, R.E.: "Evaluation of transmission network capacity use for wheeling transactions", IEEE Trans., 1989, PWRS-4, (4), pp. $1405-1413$

[9] Bialek, J.: "Topological generation and load distribution factors for supplement charge allocation in transmission open access", IEEE Trans., 1997, PWRS-12, (3), pp. 1185-1193.

[10] Su, C.T., and Liaw, J.H.: "Power wheeling pricing using power tracing andMVA-KM method". Proc. Power Tech., IEEE Porto, 10-13 Sept. 2001, Vol. 1, pp. SSM1-212

[11] Kirschen, D., Allen, R., and Strbac, G.: "Contributions of individual generators to loads and flows", IEEE Trans., 1997, PWRS-12, (1), pp. 52-60

12] Kirschen, D., and Strbac, G.: "Tracing active and reactive power between generators and loads using real and imaginary currents", IEEE Trans., 1999, PWRS-14, (4), pp. 1312-1319

[13] Wei, P., Yuan, B., Ni, Y., and Wu, F.F.: "Power flow tracing for transmission open access". Proc. 2000 IEEE Electric Utility Deregulation and Restructuring and Power Technologies, April 2000, pp. 476-481

[14] Chira Achayuthakan, Chris J. Dent, Janusz W. Bialek, Weerakorn Ongsakul,"Electricity Tracing in Systems With and Without Circulating Flows: Physical Insights and Mathematical Proofs", IEEE Trans. Power Syst., vol. 25, No. 2, pp. 1078-1087, May 2010.

[15] 'An introduction to pool rules', The Electricity Pool of England and Wales, Prepared March 1991, updated December 1991 and April 1993, P3.

[16] Rudnick. H., Palma. R., and Fernandez. J. E., "Marginal pricing and supplement cost allocation in transmission open access', IEEE Trans., 1995, PWRS-10, (2), pp. 1125-1142.

[17] Bialek,J., "Identification of source-sink connections in transmission networks". Proceedings of fourth IEE conference on Power system control and management, London, April 1996.

18] Bialek,J. and Tam. D.B,: 'Tracing the generators output' Proceedings of IEE international conference on opportunities and advances in int. electric power generation, Durham, UK, Marrch 1996

[19] Kirschen D, Allan R, Strbac G. Contributions of individual generators to loads and flows. Presented at the 1996 IEEE Power Engineering Society's Winter Power Meeting, Paper 96 WM 173-5.

[20] P.V. Satyaramesh, C. RadhaKrishna, "Usage-based transmission loss allocation under open access in deregulated power systems", IET Gener. Transm. Distrib., 2010, Vol. 4, Iss. 11, pp. 1261-1274.

[21] Singh H., Paralexopoulos A.: 'Competitive procurement of ancillary services by an independent system operator', IEEE Trans. Power Syst., 1999, 14, (2), pp. 498-504

[22] Berizzi A., Bovo C., Marannino P.: 'Allocation of transmission losses in presence of both bilateral and pool market models'. Second IEEE Power Engineering Society Int. Conf. on Power Industry Computer Applications - Innovative Computing for Power - Electric Energy Meets the Market., pp. 336-341

[23] Huang G., Zhang H.: 'Transaction based power flow analysis for transmission utilization allocation'. Proc. IEEE Power Engineering Society Summer Meeting, 2001, vol. 2
[24] J. B. Cardell, "Marginal loss pricing for hours with transmission congestion," IEEE Trans. Power Syst., vol. 22, no. 4, pp. 14661474, Nov. 2007

[25] J. N. Y. Cheung, T. Czaszejko, and A. B. Morton, "Transmission loss evaluation in an open electricity market using an incremental method," IET Gener. Transm. Distrib., vol. 1, no. 1, pp. 189-196, Jan. 2007.

[26] Y. H. Moon, H. S. Hong, H. S. Ryu, B. K. Choi, and J. D. Park, "Slack-bus independent penalty factor for regional spot pricing under deregulation,” Int. J. Elect. Power Energy Syst., vol. 24, pp. 821-826, 2002.

[27] G. Gross and S. Tao, "A physical-flow-based approach to allocating transmission losses in a transaction framework," IEEE Trans. Power Syst., vol. 15, no. 2, pp. 631-637, May 2000.

[28] R. Nadira et al., "Bulk transmission system loss analysis," IEEE Trans.Power Syst., vol. 8, no. 2, pp. 405-417, May 1993.

[29] Q. Ding and A. Abur, "Transmission loss allocation in a multiple transaction framework," IEEE Trans. Power Syst., vol. 19, no. 1, pp. 214-220, Feb. 2004

[30] J. Conejo, F. D. Galiana, and I. Kockar, "Z-bus loss allocation," IEEE Trans. Power Syst., vol. 16, no. 1, pp. 105-110, Feb. 2001.

[31] J. J. Grainger and W. D. Stevenson, Jr., Power System Analysis. New York: McGraw-Hill, 1994, pp. 329-356.

[32] J. Conejo, J. M. Arroyo, N. Alguacil, and A. L. Guijarro, "Transmission loss allocation: A comparison of different practical algorithms," IEEE Trans. Power Syst., vol. 17, no. 3, pp. 571-576, Aug. 2002.

[33] Sinha N, Chakrabarti R, Chattopadhyay PK. Evolutionary programming techniques for economic load dispatch. IEEE Trans Evol Comput 2003;7(1):83-94.

[34] Victoire T Aruldoss Albert, Ebenezer A Jeyakumar. Hybrid PSOSQP for economic dispatch with valve-point effect. Electr Power Syst Res 2004;71(1):51-9.

[35] Dos Santos Coelho Leandro, Mariani Viviana Cocco. Particle swarm approach based on quantum mechanics and harmonic oscillator potential well for economic load dispatch with valvepoint effects. Energy Convers Manage 2008;49(11):3080-5.

[36] Noman N, Iba H. Differential evolution for economic load dispatch problems. Electric Power Syst Res 2008;78(8):1322-31.

[37] Hemamalini S, Simon Sishaj P. Artificial bee colony algorithm for economic load dispatch problem with non-smooth cost functions. Electr Power Comp Syst 2010;38(7):786-803.

[38] Panigrahi BK, Yadav Salik R, Agrawal S, Tiwari MK. A clonal algorithm to solve economic load dispatch. Electr Power Sys Res 2007;77(10):1381-9.

[39] Cai JJ, Ma XQ, Li LX, Peng HP. Chaotic particle swarm optimization for economic dispatch considering the generator constraints. Energy Convers Manage 2007;48(2):645-53.

[40] Wong KP, Algie C. Evolutionary programming approach for combined heat and power dispatch. Elect Power Syst Res 2002;61:227-32

[41] Basu M. Bee colony optimization for combined heat and power economic dispatch. Expert Sys Appl 2011;38(11):13527-31.

[42] Mohammadi-Ivatloo B, Moradi-Dalvand M, Rabiee A. Combined heat and power economic dispatch problem solution using particle swarm optimization with time varying acceleration coefficients. Electr Power Syst Res 2013;95:9-18.

[43] Wang L, Li LP. An effective differential harmony search algorithm for the solving non-convex economic load dispatch problems. Int J Electr Power Energy Syst 2013;44(1):832-43.

[44] Panigrahi BK, Pandi VR, Das S. Adaptive particle swarm optimization approach for static and dynamic economic load dispatch. Energy Convers Manage 2008;49(6):1407-15.

[45] Durairaj S, Devaraj D, Kannan PS. Genetic algorithm applications to optimal reactive power dispatch with voltage stability enhancement. IE (I) J-EL 2006;87:42-7.

[46] Devaraj D. Improved genetic algorithm for multi-objective reactive power dispatch problem. Eur Trans Electr Power 2007;17:569-81.

[47] Devaraj D, Durairaj S, Kannan PS. Real parameter genetic algorithm to multiobjective reactive power dispatch. Int J Power Energy Syst 2008;28(1):1710-2243.

[48] Wu QH, Cao YJ, Wen JY. Optimal reactive power dispatch using an adaptive genetic algorithm. Int $\mathrm{J}$ Electr Power Energy Syst 1998;20(8):563-9. 
[49] Wu QH, Ma JT. Power system optimal reactive power dispatch using evolutionary programming. IEEE Trans Power Syst 1995;10(3):1243-9.

[50] Yoshida H, Kawata K, Fukuyama Y, Takamura S, Nakanishi Y. A particle swarm optimization for reactive power and voltage control considering voltage security assessment. IEEE Trans Power Syst 2000;15(4):1232-9

[51] Esmin AAA, Lambert-Torres G, De-Souza ACZ. A hybrid particle swarm optimization applied to loss power minimization. IEEE Trans Power Syst 2005;20(2):859-66.

[52] Tripathy M, Mishra S. Bacteria foraging-based solution to optimize both real power loss and voltage stability limit. IEEE Trans Power Syst 2007;22(1):240-8.

[53] Ela AAAE, Abido MA, Spea SR. Differential evolution algorithm for optimal reactive power dispatch. Electr Power Syst Res 2011;81:458-64.

[54] Liang CH, Chung CY, Wong KP, Duan XZ, Tse CT. Study of differential evolution for optimal reactive power flow. IEE Proc Gen Trans Distrib 2007;1(2):253-60.

[55] Varadarajan M, Swarup KS. Network loss minimization with voltage security using differential evolution. Electr Power Syst Res 2008;78:815-23.

[56] Dai C, Chen W, Zhu Y, Zhang X. Seeker optimization algorithm for optimal reactive power dispatch. IEEE Trans Power Syst 2009;24(3):1218-31.

[57] Duman S, So€nmez Y, Gu€venc U, Yo€ru€keren N. Optimal reactive power dispatch using a gravitational search algorithm. IET Gener Transm Distrib 2012;6(6):563-76.

[58] Zhang J, Sanderson AC. JADE: adaptive differential evolution with optional external archive. IEEE Trans Evol Compt 2009;13(5):945-58.

[59] Rashedi E, Nezamabadi-pour H, Saryazdi S. GSA: a gravitational search algorithm. Inf Sci 2009;179(13):2232-48.

[60] Enrique Acha, Claudio R.Fuerte-Esquivel," FACTS Modelling and Simulationin Power Networks", JOHN WILLY \& SONS LTD, 2004, pp.311-340

\section{BIOGRAPHY}

N.V. Subba Rao obtained his MTech degree from J.N.T. University, Kakinada, India. He is currently working as an Associate Professor in L.B. Reddy College of Engineering, Mylavaram in Andhra Pradesh, India.

$\mathrm{He}$ is currently pursuing his $\mathrm{PhD}$ in J.N.T. University, Kakinada. He is an associate member of Institution of Engineers, India. His areas of interest are power system deregulation and modeling of induction generators.

Dr. G. Kesava Rao obtained his $\mathrm{PhD}$ from Moscow Power Engineering Inst. Moscow, U.S.S.R. He worked in Institute of Technology at Banaras Hindu University, Varanasi, India in various administrative and academic positions. Currently, he is working as professor in KL University, Guntur, A.P., India. His fields of interest are power system deregulation and renewable energy sources.

Dr. S. Sivanagaraju is Professor in the department of Electrical and Electronics Engineering, University College of Engineering Kakinada, Jawaharlal Nehru Technological University Kakinada, Kakinada, A.P., India. He completed his Master's degree from Indian Institute of Technology, Khargpur, India, in electrical power systems. He completed his doctoral program from Jawaharlal Nehru Technological University Hyderabad, Andhra Pradesh, India. His interests include FACTS Controllers, Electrical Distribution System Automation, Optimization Techniques, Voltage Stability, Power System Analysis, and Power System Operation and Control. 